Research Article

\title{
An Intelligent Evaluation Method to Analyze the Competitiveness of Airlines
}

\author{
Jun Zhao $i$ and Xumei Chen \\ School of Traffic and Transportation, Beijing Jiaotong University, Beijing 100044, China \\ Correspondence should be addressed to Xumei Chen; xmchen@bjtu.edu.cn
}

Received 6 June 2020; Revised 4 August 2020; Accepted 17 August 2020; Published 7 September 2020

Guest Editor: Jun Shen

Copyright () 2020 Jun Zhao and Xumei Chen. This is an open access article distributed under the Creative Commons Attribution License, which permits unrestricted use, distribution, and reproduction in any medium, provided the original work is properly cited.

\begin{abstract}
An intelligent evaluation method is presented to analyze the competitiveness of airlines. From the perspective of safety, service, and normality, we establish the competitiveness indexes of traffic rights and the standard sample base. The self-organizing mapping (SOM) neural network is utilized to self-organize and self-learn the samples in the state of no supervision and prior knowledge. The training steps of high convergence speed and high clustering accuracy are determined based on the multistep setting. The typical airlines index data are utilized to verify the effect of the self-organizing mapping neural network on the airline competitiveness analysis. The simulation results show that the self-organizing mapping neural network can accurately and effectively classify and evaluate the competitiveness of airlines, and the results have important reference value for the allocation of traffic rights resources.
\end{abstract}

\section{Introduction}

Traffic rights are the most competitive resources for airlines to enter the international aviation market. According to the convention on the International Civil Aviation (Chicago Convention), civil aviation authorities of each country can sign a bilateral or multilateral air transport agreement, which stipulates the right of each designated airline to operate an agreed flight on a prescribed route. Based on the different agreements, some countries do not limit the number of designated carriers, route list, and capacity quota for airlines. Airlines can arrange flight plans according to route network planning and market demand, such as China and the Association of Southeast Asian Nations (ASEAN) countries. Other countries have set restrictions on the operation rights of airlines, and the resources of traffic rights are relatively scarce. There exists competition for the traffic rights among the airlines. The reasonable allocation of these traffic rights resources is of great significance to the aviation transport market. There are many experiences in the airline management of other countries. The most reasonable allocation basis for the traffic rights resources is based on the competitiveness ranking of the airlines.
The experts and scholars have studied the competitiveness of airlines deeply. The competitiveness of airlines can be measured in terms of some indexes, such as normality $[1,2]$, safety $[3,4]$, service $[5,6]$, productivity [7], on-time performance [8], and market share [9] [10-12]. However, these studies of airlines' competitiveness are mainly from the perspective of airlines to acquire and retain customers in such a highly competitive market [13-15]. There is little research on the levels and competitiveness from the perspective of management departments, so as to provide a support for the allocation of the traffic rights resources. It is thus the primary purpose of this paper to evaluate and analyze the competitiveness of airlines based on the management organization.

At present, the analysis and evaluation of airline competitiveness mainly focus on the use of the analytic hierarchy process (AHP), fuzzy comprehensive evaluation, factor analysis, Delphi technique, data envelopment analysis (DEA) model, grey clustering analysis, and other methods [16-18]. Among them, Delphi technique is a qualitative method for structuring a group communication process so that the process is effective in allowing a group of individuals, as a whole, to deal with a complex problem [19]. 
Because the airlines competitiveness can be viewed as a complex problem, Delphi technique was utilized to reach a consensus among the airlines experts. The AHP technique is "a theory of measurement through pairwise comparisons and relies on the judgments of experts to derive priority scales." It can determine the priority of the key competitiveness indicators and drivers of airlines [20]. Delbari et al. investigated the competitiveness of airlines using Delphi and AHP techniques. The results revealed that the ranking of the key competitiveness drivers with respect to each indicator differs significantly [21]. Yu and Li [22] used the multilevel fuzzy comprehensive evaluation method to carry out the empirical analysis and the competitiveness analysis of network airlines, so as to solve the fuzzy problem of evaluation indexes and evaluation grades. Fu and $\mathrm{Wu}$ [23] established a simple fuzzy analytic hierarchy process of the competitiveness evaluation model of airlines and analyzed the changes of the competitiveness level of airlines in different periods. Li et al. [24] chose the entropy weight extension matter-element model to evaluate the competitiveness of airlines. He believed that airlines can cultivate the competitiveness according to the evaluation results. $\mathrm{Li}$ and $\mathrm{Wu}$ [25] established a two-stage analysis model reflecting the subjective and effective efforts of airline managers and selected 15 domestic airlines as empirical samples to analyze the competitiveness ranking of each airline. Bai et al. used the DEA model to establish an evaluation method to evaluate the airline's service quality. This method does not need explicit expression of the relationship between input and output, and the result has certain practical value $[26,27]$. The abovementioned correlation analysis mainly relies on the model to evaluate the competitiveness of airlines, and the methods mainly rely on the experience and evaluation of experts themselves, which is subjective and lacks the direct reflection of relevant data.

In order to ensure the fairness of the analysis, we use a novel algorithm of self-organizing feature mapping neural network to model and analyze. The self-organization map network has good self-organization, self-adaption, and robustness [28]. It can learn or simulate the unknown environment or sample space without prior knowledge and can deal with quantitative and qualitative knowledge at the same time [29-31], which avoids the subjective evaluation of the competitiveness of airlines. Due to the use of self-learning without teachers, it is a recognition network based on small sample training, which is different from the traditional neural network that requires a large number of training samples to ensure the accuracy of the analysis [32-36]. It is of certain significance for the analysis of the small sample size of the competitiveness of airlines. In addition, there are many factors in the competitiveness of airlines. The network model has the characteristics of distribution [37, 38], which is quite suitable for the study of the classification mechanism of the competitiveness of the airlines. Therefore, this paper uses the index data of traffic rights as feature samples to input SOM neural network for competitiveness analysis and clustering and uses the index data of typical airlines as an example to verify, so as to determine the level of competitiveness of each airline.
In the subsequent sections, we first analyze the key performance indexes suitable for evaluating competitiveness of the airlines. Next, we develop a self-organizing mapping neural network model and design an algorithm process to evaluate the airlines. We then establish a standard sample library to train the SOM network and utilize the actual data to obtain the airline competitiveness results. Finally, we conduct a discussion to compare the SOM neural network method with the grey clustering analysis so as to verify the effectiveness of the method.

\section{Determination of Traffic Right Indexes}

In China, the civil aviation transportation industry is a fully competitive service industry. Management organizations mainly evaluate and choose airlines through the dimensions of safety, service, and normality. Here, we mainly stand in the perspective of management organizations to make the safety, normality, and service as the basic indexes to evaluate the level of competitiveness. Among them, safety is the foundation of civil aviation operation, and service and normality are the key links of airline competitiveness. These three dimensions constitute the basic indexes of airline competitiveness evaluation and analysis. Considering the perspective of safety, service, and normality, this paper selects four indexes, namely, the ten-thousand-hour rate of flight accidents, the abnormal rate of flights caused by the airline, the rate of passenger complaints, and the rate of flight plan execution, for the evaluation and analysis of the airline competitiveness.

The ten-thousand-hour rate of flight accidents refer to the events that affect or may affect flight safety in every tenthousand-hour flight activities. It is the core evaluation index for the safe operation of airlines. The abnormal rate of flights caused by the airline refers to the percentage of abnormal flights caused by airline's own reasons in the number of scheduled flights in the assessment cycle. It objectively reflects the flight operation organization and enterprise service management level of the airline and is an important index to assess the operation quality of the airline. The passenger complaint rate refers to the percentage between the number of passenger complaints and passenger traffic volume, which is the main measure of passengers' satisfaction with the transportation services provided by airlines. The rate of flight plan execution refers to the percentage of the actual and planned flight volume of the airline, which reflects the core index of the efficiency of the airline's flight execution.

\section{A Self-Organizing Mapping Neural Network}

3.1. SOM Network Model. SOM is a new unsupervised competitive learning feedforward neural network model. Considering the unique attributes of SOM model, self-organization and feature mapping, SOM has its core characteristics, that is, fully and effectively retaining the neuron topology. Due to this feature, the winning neuron of the network model and its neighborhood neuron adjust the weight together, and the neighborhood of the neuron is more sensitive to the specified input. In the analysis competitiveness 
of the airlines, the determination of index weight avoids the situation that the weight is easily influenced by personal subjective opinions when the weight is determined artificially. At the same time, it avoids the situation that the weight is easily inconsistent with the actual state when it is determined completely according to the numerical value. The analysis result is more stable and efficient.

Firstly, a self-organizing feature mapping neural network model is constructed, which is composed of input layer and competition layer (output layer). The number of neurons in the input layer is $n$. Set the characteristic input node, $x_{1}, x_{2}, \ldots, x_{n}$. The competition layer is the output layer, which is a two-dimensional plane array composed of $a \times b$ neurons. Each input neuron is connected with all the neurons in the two-dimensional plane array. The training process of SOM network is to constantly adjust the connection weight of network nodes, so that different input types correspond to different neurons in the two-dimensional plane array. Figure 1 shows the structure of the model.

As shown in Figure 1, each node of the competition layer is arranged into a neighborhood mode in some specific form, which specifies the neighborhood structure of each neuron and the location of characteristic nodes belonging to the domain or excluding from the neighborhood. According to the results of the network specific identification and classification, all nodes in the output layer are connected or partially connected. All input nodes and output nodes between input layer and competition layer are connected by weight. This ensures that in the process of SOM neural network training, not only the weights and thresholds corresponding to the winning neuron will be adjusted but also other neurons in the adjacent range will have the opportunity to adjust the weights and thresholds, which guarantees the good learning ability and generalization ability of SOM neural network.

3.2. Algorithm Process. The input of the SOM is the competitiveness index value of each airline. Then, the input sample set is classified. The index component parameter vector corresponds to the neuron weight vector of the output layer one by one. In order to clearly describe the learning process of network model, the flowchart of SOM network model learning algorithm is constructed as shown in Figure 2.

3.2.1. Initialization. Generally, any value in the interval $[0$, 1] of the weight vector will be given, expressed in $W$. The weight vector $W=\left[w_{i 1}, w_{i 2}, \ldots, w_{i N}\right]^{T}(i=1,2, \ldots, N)$. The learning rate is $\eta, \eta \in[0,1]$.

3.2.2. Set the Input Vector. The input vector is composed of indicators, that is, the training samples of the network model are

$$
X=\left[x_{1}, x_{2}, x_{3}, \ldots, x_{N-1}, x_{N}\right]^{T} .
$$

3.2.3. Derive the Euclidean Distance. $W_{i j}$ represents the weight of the neuron $i$ in the input layer and the neuron $j$ in the mapping layer. The Euclidean distance between the input

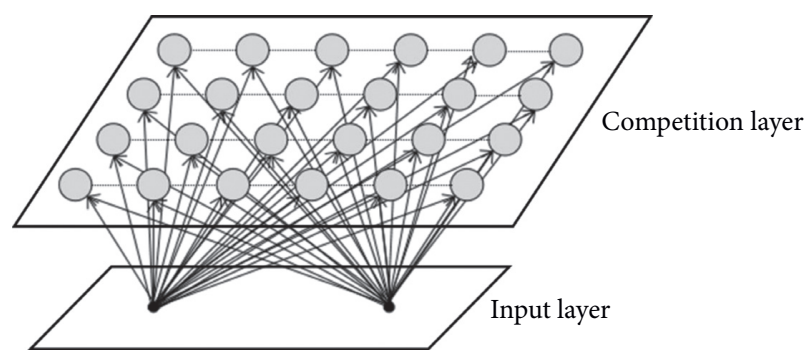

Figure 1: Network model of SOM.

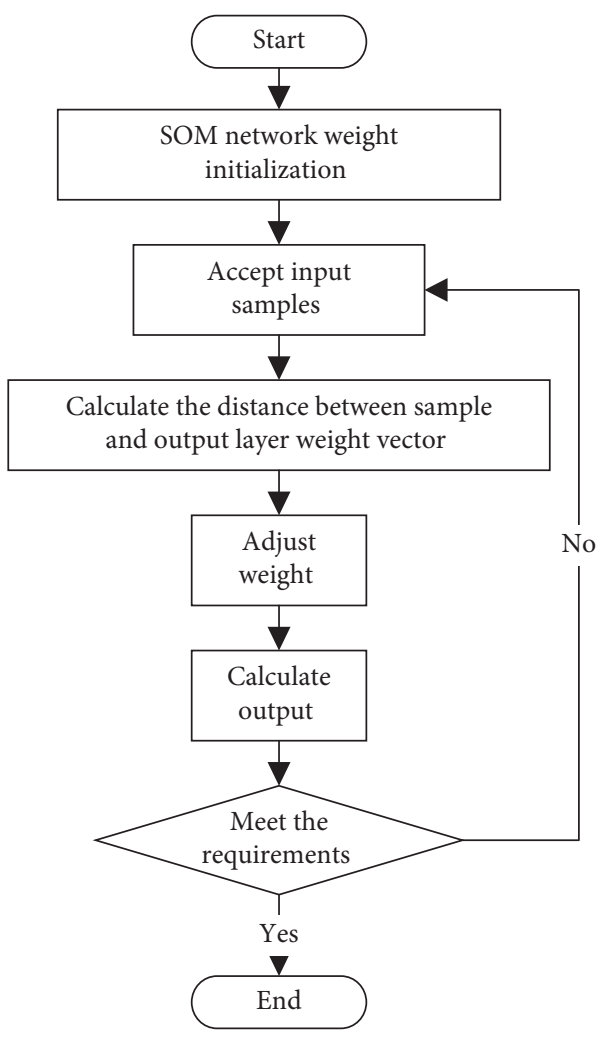

FIGURE 2: SOM network algorithm flowchart.

vector and the weight vector is derived to obtain the specific location of the neuron. The Euclidean distance $d_{i}$ is calculated by

$$
d_{i}=\left\|X-W_{j}\right\|=\sqrt{\sum_{i=1}^{n}\left[x_{i}(t)-w_{i j}(t)\right]^{2}} .
$$

3.2.4. Label the Winning Neurons. The position of the winning neuron is the minimum neuron position of Euclidean distance between the input vector and the weight vector. The Euclidean distance between the input vector and the weight vector is expressed by $\|\cdot\|$. When the input vector is $X$, the $t$-th neuron wins, which needs to meet the following requirements: 


$$
\left\|X-W_{i}\right\|=\min _{i}\left\|X-W_{i}\right\|, \quad i=1,2,3, \ldots, N-1, N
$$

3.2.5. Cooperation of Topological Neighborhood Neurons. The winning neurons are located in the center of the topological neighborhood and consist of single or group neurons. According to the construction of network model, the shape of neighborhood is selected. Common neighborhood geometry includes linear neighborhood, square neighborhood, polygon neighborhood, etc. In order to improve the efficiency of cooperation, this paper chooses hexagon neighborhood as the neighborhood shape of airline competitiveness network model, as shown in Figure 3.

In the process of training, the neighborhood radius and the number of winning neurons gradually increase. As the only index to determine the size of neighborhood, the radius of topological neighborhood is recorded as $N_{i}(n)$, which represents the radius of topological neighborhood under $n$ times of superposition, that is, the area of neighborhood. It changes with time. The rule is described by equation (4), and the neighborhood change under the specified conditions is described in Figure 4:

$$
N_{i}(n)=\operatorname{INT}\left(N_{i}(0)\left(1-\frac{n}{N}\right)\right), \quad n=1,2,3, \ldots, N,
$$

where INT(.) is to round the function, $N_{i}(0)$ is the initial value of the topological neighborhood, and $N$ is the total number of iterations.

3.2.6. Adjust the Weight. The weight vector of all winning neurons in the neighborhood is updated until the recognition results meet the specific requirements of the first set competitiveness level judgment. The updating adopts the Hebb learning method. According to equation (5), the connection weights of input neurons and neighboring neurons are modified:

$$
\Delta w_{i j}=w_{i j}(t+1)-w_{i j}(t)=\eta(t)\left[x_{i}(t)-w_{i j}(t)\right],
$$

where $\eta(t)$ is the learning rate at time $t, \eta(t) \in[0,1] . \eta(t)$ decreases gradually with the increase of time and is inversely proportional to $t$, and its expression is

$$
\begin{aligned}
\eta(t) & =\frac{1}{t}, \\
\text { or } \eta(t) & =0.2\left(1-\frac{t}{1000}\right) .
\end{aligned}
$$

3.2.7. Calculate the Output Value $O_{k}$. The calculation output value is given as

$$
O_{k}=f\left(\min \left\|X-W_{j}\right\|\right) .
$$

Then judge whether the output results meet the requirements of the preset competitiveness level. If the result meets the requirements of the competitiveness level, export

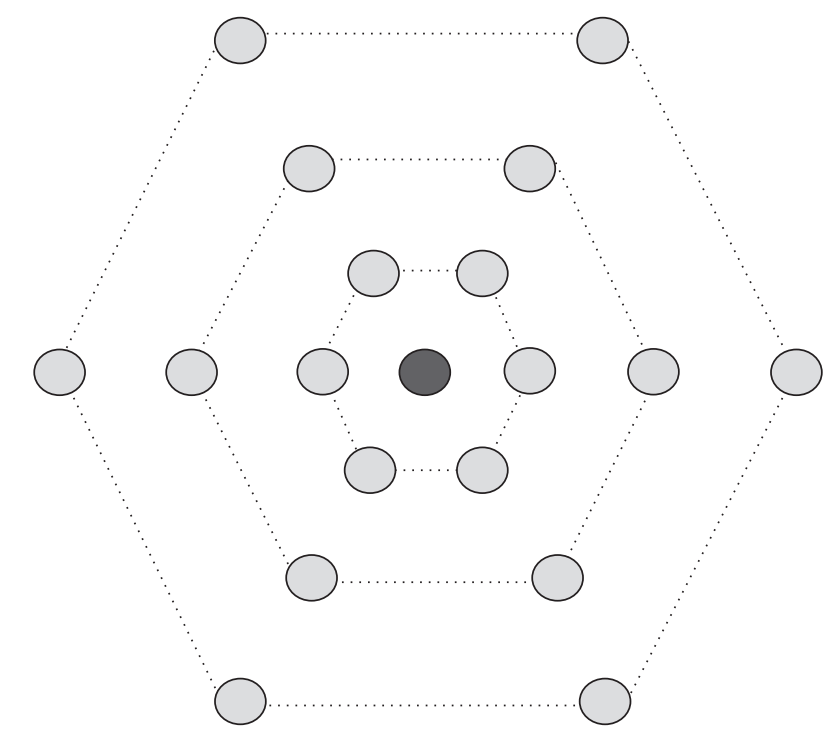

FIGURE 3: Neighborhood of airline competitiveness network model.

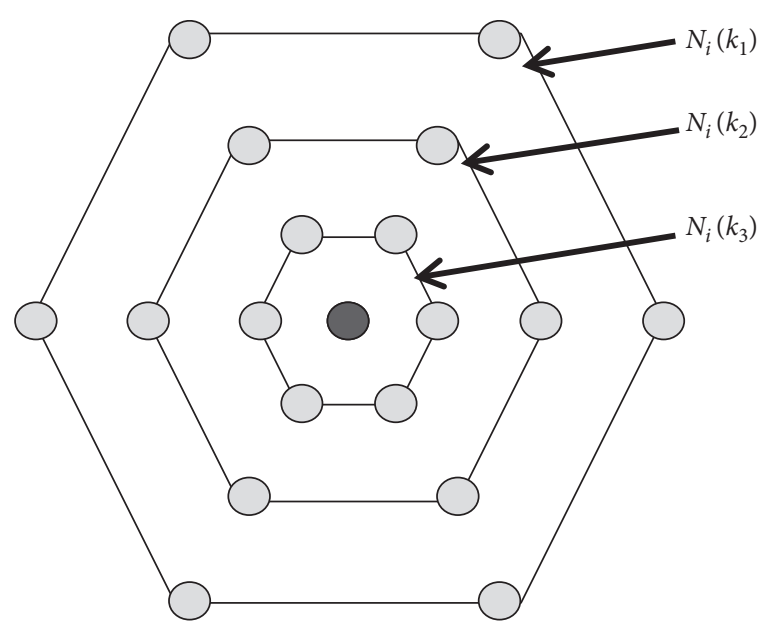

FIGURE 4: Topological neighborhood change of hexagon.

the competitiveness level; if the result does not meet the requirements of competitiveness level, return to step (2) to continue learning until it meets the results of competitiveness level.

\section{Analysis of Airline Competitiveness Results}

4.1. Standard Sample Library. Using the factors of competitiveness introduced in Section 1, four main indexes are selected for testing: the ten thousand-hour rate of flight accidents, the abnormal rate of flights caused by the airline, the rate of passenger complaints, and the rate of flight plan execution. In this paper, four linguistic variables are selected, and the evaluation characteristics are divided into "excellent," "good," "general," and "poor." The index values of the 20th percentile, the 40th percentile, the 60th percentile, and the 80th percentile of each index of airlines are taken as the standard samples of four evaluation characteristics, as shown in Table 1. 
TABLE 1: Standard sample.

\begin{tabular}{lccc}
\hline $\begin{array}{l}\text { Evaluation } \\
\text { characteristics }\end{array}$ & $\begin{array}{c}\text { Ten-thousand-hour rate of flight } \\
\text { accidents }\end{array}$ & $\begin{array}{c}\text { Abnormal rate of flights caused by } \\
\text { airline }\end{array}$ & $\begin{array}{c}\text { Rate of passenger } \\
\text { complaints }\end{array}$ \\
\hline Excellent & 0.0000 & 0.1493 & $\begin{array}{c}\text { Rate of flight } \\
\text { plan } \\
\text { execution }\end{array}$ \\
Good & 0.0072 & 0.1542 & 0.2108 \\
General & 0.0446 & 0.1572 & 0.2273 \\
Poor & 0.1382 & 0.1596 & 0.2444 \\
\hline
\end{tabular}

4.2. SOM Network Training. The evaluation grade and the four indexes of the corresponding index types (i.e., the ten thousand-hour rate of flight accidents, the abnormal rate of flights caused by the airline, the rate of passenger complaints, and the rate of flight plan execution in Table 1) is taken in the standard sample as the input vector of SOM network $[x 1, x 2$, $x 3, x 4]$. The competition layer of the network is set as $6 \times 6=36$ neurons; the number of training steps is set as 10 , $50,100,200,500$, and 1000. The classification effect of different training steps in the SOM network training process is shown in Table 2, where different numbers represent different classification numbers. Figure 5 shows the topology of the winning neurons in different steps.

It can be seen from Table 2 and Figure 5 that, when the number of training steps is 10 , excellent and good can be divided into one category and general and poor can be divided into one category. The SOM network only preliminarily classifies standard samples. When the number of training steps increases to 50 and 100, the classification accuracy will be further improved with the gradual increase of training steps, so as to distinguish excellent, good, and general. When the number of training steps reaches 200, the four evaluation levels are completely distinguished. At this time, if we continue to increase the number of training steps to 500 or even 1000 , each sample is divided into one category, which has no practical significance. Therefore, 200 steps are the best number of training steps. According to the number of excellent, good, general, and poor neurons corresponding to the 200 step training in Table 2, we can see that the competitive winning neurons in four situations are 7,26, 30, and 6, respectively, as shown in the grey hexagon in Figure 5 (4). Each neuron has a topological position, that is, $(x, y)$ in the neuron coordinates. It can be seen that the corresponding states of four types of standard samples are clearly distinguished in the two-dimensional array.

4.3. Application and Validation. In order to validate the effect of SOM neural network on airline competitiveness analysis, 20 typical Chinese airlines index data of 2019 are selected. The data are from the transportation department of Civil Aviation Administration of China. The SOM neural network trained in Section 3.2 is input to get airline competitiveness analysis results.

Combining Table 3 and Figure 6, it can be seen that the category label of sample nos. $1,7,10,16$, and 19 is 7 , which belongs to the excellent category label of clustering results; the category label of sample nos. $6,8,9,11$, and 20 is 26 ,
TABle 2: Clustering results for different training steps.

\begin{tabular}{lcccc}
\hline \multirow{2}{*}{ Train steps } & \multicolumn{4}{c}{ Clustering results } \\
& Excellent & Good & General & Poor \\
\hline 10 & 7 & 7 & 30 & 30 \\
50 & 7 & 7 & 30 & 6 \\
100 & 7 & 26 & 30 & 30 \\
200 & 7 & 26 & 30 & 6 \\
500 & 8 & 26 & 23 & 6 \\
1000 & 14 & 26 & 36 & 6 \\
\hline
\end{tabular}

which belongs to the good category label of clustering results; the category labels of sample nos. 2, 5, 13, 17, and 18 is 30 , which belongs to the general category labels of clustering results; the category labels of sample nos. 3, 4, 5, 12, 14, and 15 is 6 , which belongs to the poor category label of clustering results. The evaluation results above are mostly consistent with the actual situation. The above results can accurately predict the competitiveness of different airlines. The results have a certain reference value for the allocation of traffic rights.

Similarly, we select 20 typical Chinese airlines index data of the past 5 years. The index data are input into SOM neural network to analyze the competitiveness evaluation results of the airlines. The evaluation accuracy $\mathrm{TP}$ is calculated as follows:

$$
\mathrm{TP}=\frac{1}{n} \sum_{i=1}^{n} \frac{X_{i}-E_{i}}{X_{i}}
$$

Among them, $n$ represents the data year, $X_{i}$ represents the total amount of the samples in the $i$-th year, $E_{i}$ represents the error samples in the $i$-th year, and TP represents the evaluation accuracy. According to the calculation of the prediction results, $\mathrm{TP}=94.8 \%$. The evaluation accuracy is within a reasonable range. The above prediction results and evaluation accuracy have a good clustering and evaluation effect for the competitiveness analysis of airlines. It has a certain value for the aviation authority to allocate scarce traffic right resources, so that airlines pay more attention to safety, normality, and service, form a benign competition and ultimately enhance the overall competitiveness of the industry.

\section{Discussions}

The SOM neural network herein is utilized to conduct a cluster evaluation of the airlines. In the previous studies, the grey clustering analysis is an evaluation method to analyze 


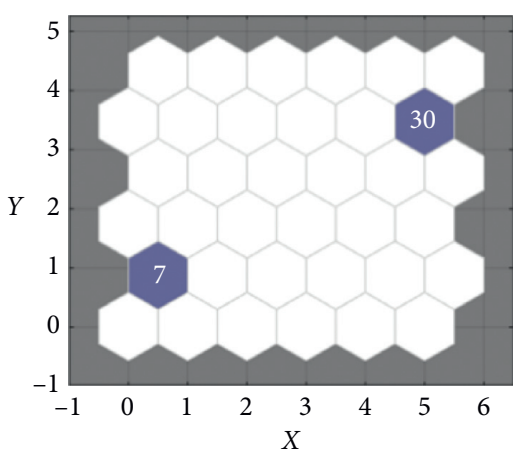

(a)

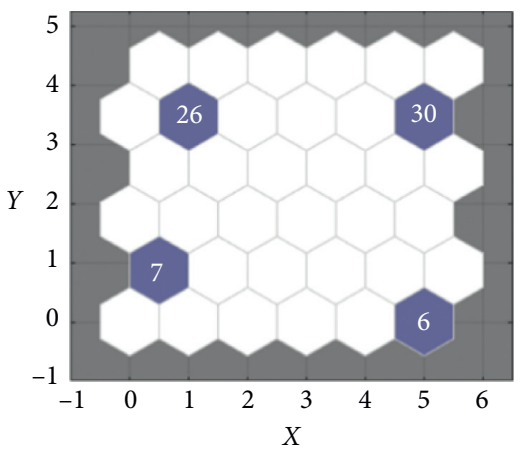

(d)

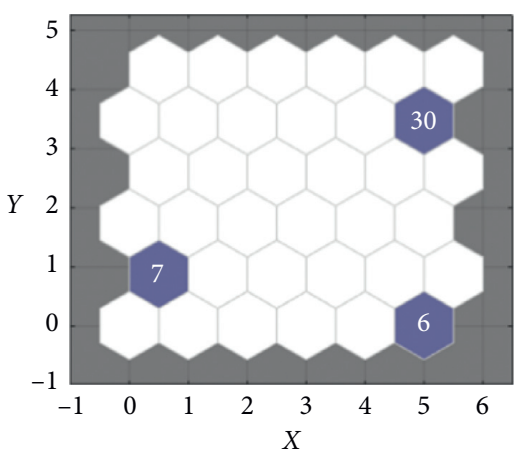

(b)

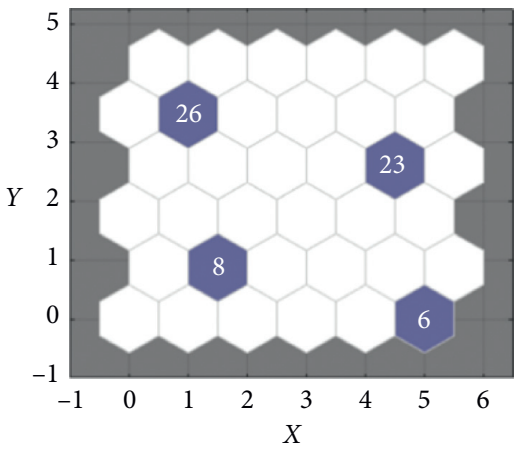

(e)

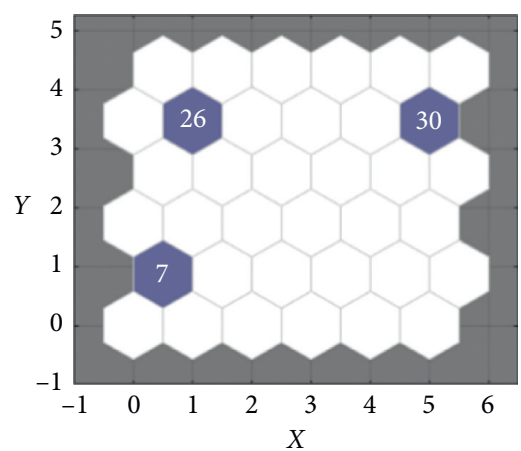

(c)

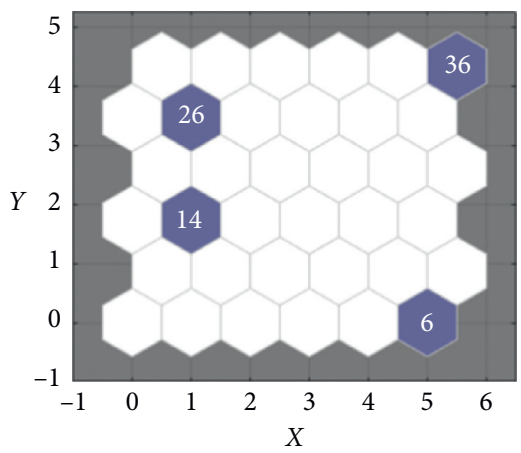

(f)

Figure 5: Topology of winning neurons with asynchronous number. (a) 10 steps. (b) 50 steps. (c) 100 steps. (d) 200 steps. (e) 500 steps. (f) 1000 steps.

TABLE 3: Sample airline data.

\begin{tabular}{|c|c|c|c|c|}
\hline $\begin{array}{l}\text { Sample } \\
\text { label }\end{array}$ & $\begin{array}{c}\text { Ten-thousand-hour rate of flight } \\
\text { accidents }\end{array}$ & $\begin{array}{c}\text { Abnormal rate of flights caused by } \\
\text { airline }\end{array}$ & $\begin{array}{l}\text { Rate of passenger } \\
\text { complaints }\end{array}$ & $\begin{array}{c}\text { Rate of flight } \\
\text { plan } \\
\text { execution }\end{array}$ \\
\hline 1 & 0.0000 & 0.1458 & 0.2438 & 0.9902 \\
\hline 2 & 0.0230 & 0.1472 & 0.2042 & 0.4173 \\
\hline 3 & 0.1310 & 0.1525 & 0.8897 & 0.3492 \\
\hline 4 & 0.1430 & 0.1568 & 0.2470 & 0.4473 \\
\hline 5 & 0.0000 & 0.1587 & 0.2290 & 0.3966 \\
\hline 6 & 0.0000 & 0.1602 & 0.2206 & 0.6667 \\
\hline 7 & 0.0090 & 0.1668 & 0.3074 & 0.8615 \\
\hline 8 & 0.0680 & 0.1677 & 0.2859 & 0.7396 \\
\hline 9 & 0.0060 & 0.1765 & 0.3897 & 0.8258 \\
\hline 10 & 0.0180 & 0.1776 & 0.2832 & 0.8895 \\
\hline 11 & 0.0000 & 0.1793 & 0.1958 & 0.6674 \\
\hline 12 & 0.1320 & 0.1823 & 0.7352 & 0.5384 \\
\hline 13 & 0.0000 & 0.1927 & 0.4982 & 0.8219 \\
\hline 14 & 0.0000 & 0.1953 & 0.4810 & 0.5000 \\
\hline 15 & 0.0000 & 0.1958 & 0.2594 & 0.3418 \\
\hline 16 & 0.0390 & 0.2075 & 0.0000 & 0.8986 \\
\hline 17 & 0.0000 & 0.2139 & 0.3597 & 0.7738 \\
\hline 18 & 0.0160 & 0.2317 & 0.3415 & 0.6035 \\
\hline 19 & 0.0000 & 0.2516 & 0.1886 & 0.7813 \\
\hline 20 & 0.0210 & 0.1817 & 0.2958 & 0.8032 \\
\hline
\end{tabular}

Note: data are from Civil Aviation Administration of China.

the airlines. As described in reference [39], the operation and service quality of the airlines was evaluated and analyzed based on the grey clustering analysis. The whitening weight function is determined the experience, which has a certain of subjectivity as shown in Figure 7. Through the analysis of index data of 20 typical domestic airlines from July to 


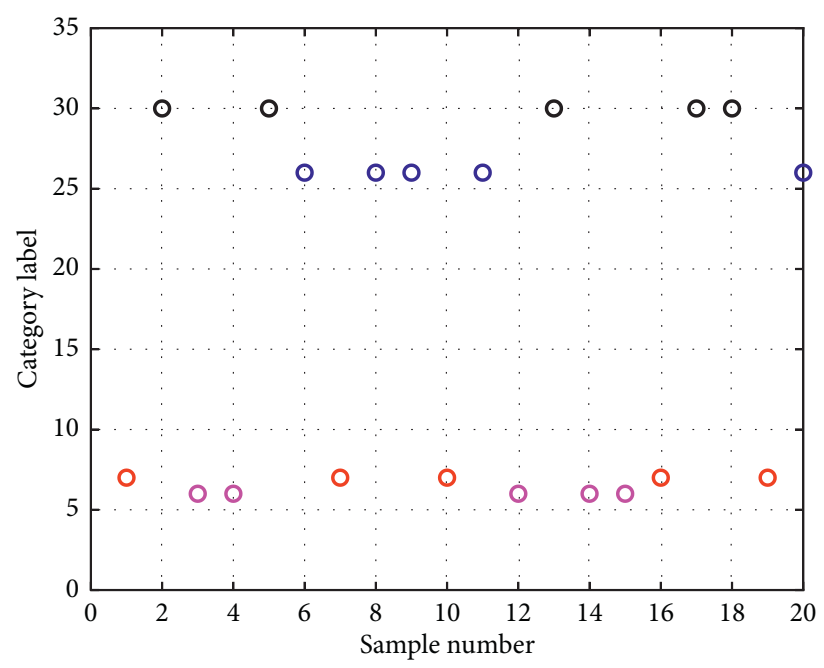
O Excellent clustering results
O General clustering results O Good clustering results O Poor clustering results

FIGURE 6: Sample forecast classification.

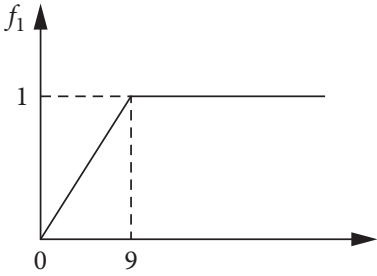

(a)

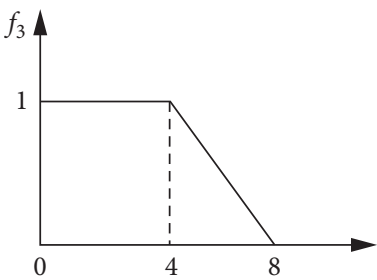

(c)

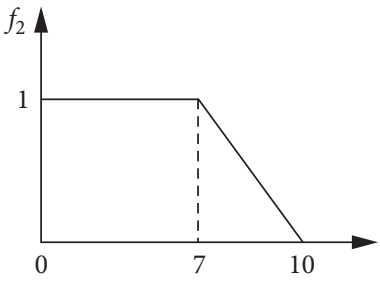

(b)

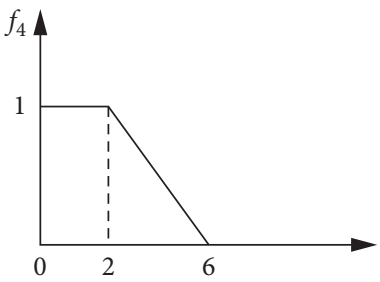

(d)

Figure 7: Whitening weight function.

December 2019, the rating of each airline's operating service quality is shown in Table 4 .

From Table 4, we can see that the quantity of the excellent level is 9 , while the quantity of the poor level is just 2 . This is because that the weight of the grey class is determined by the subjective judgment of people. The situation leads to the cluster results where fluctuations exist so that resources cannot be allocated reasonably.

In addition, we also compare the clustering method of the principal component analysis (PCA) from reference [40]. In this existing related work, principal component analysis (PCA) was used to study the index data of samples. The sample index data were standardized. According to the standardized sample index data, the covariance matrix of the factor was obtained, which was the correlation matrix of the original sample index data. Then, the contribution rate of the
TABLE 4: Evaluation level.

\begin{tabular}{lc}
\hline Evaluation level & Sample serial number \\
\hline Excellent & $10,11,12,14,15,16,17,18,19$ \\
Good & $1,2,3,4,5,9$ \\
General & $6,8,20$ \\
Poor & 7,13 \\
\hline
\end{tabular}

selected principal components and the cumulative contribution rate of each principal component were calculated. The number of principal components was determined, so as to calculate the comprehensive evaluation value. Finally, the reference obtained the comprehensive score of competitiveness evaluation of five airlines in 2007-2010, as shown in Table 5. 
TABLE 5: Comprehensive score of competitiveness evaluation of five airlines in 2007-2010.

\begin{tabular}{lcccccc}
\hline Year & Airline 1 & Airline 2 & Airline 3 & Airline 4 & Airline 5 & Average score \\
\hline 2007 & 3.500 & 2.850 & 1.190 & 1.140 & 0.560 & 1.848 \\
2008 & 4.090 & 2.560 & 1.350 & 0.920 & 0.450 & 0.710 \\
2009 & 3.880 & 2.960 & 1.270 & 0.750 & 0.450 & 1.914 \\
2010 & 3.900 & 2.430 & 1.420 & 1.020 & 0.958 & 0.543 \\
Annual average score & 3.843 & 2.700 & 1.308 & & 1.844 \\
of the company & & & &
\end{tabular}

Comparing the PCA method with the proposed method, the PCA can obtain the scores of the airlines, which is more intuitive, while the selected principal components and their number are gained from the expert experience. It has certain subjectivity. The method of SOM neural network is to train and learn the standard sample library, which is more objective. And, the results will not be changed by the human factors. It is more suitable for clustering analysis of airline competitiveness.

\section{Conclusions}

This paper proposed an analysis method of competitiveness of the airlines based on SOM neural network. This method has a good judgment effect on the classification of competitiveness of the airlines. Considering the perspective of safety, service, and normality, the indexes are determined as the ten-thousand-hour rate of flight accidents, the abnormal rate of flights caused by the airline, the rate of passenger complaints, and the rate of flight plan execution. The SOM neural network is used to train and learn the standard sample library. The multistep setting is utilized to determine the number of training steps for high network convergence speed and high clustering accuracy.

The results show that the SOM neural network algorithm has a good clustering and evaluation effect on the analysis of the airline competitiveness through the verification of examples. Based on small samples of the airlines, the evaluation accuracy reached $94.8 \%$, and it was a relatively accurate evaluation accuracy. It has an important reference application value for the allocation of scarce traffic rights resources and the allocation of other key resources.

In addition, further investigation of the airline competitiveness analysis is needed. On one hand, more comprehensive index parameters on airline competitiveness need to be considered. On the other hand, using scientific calculation methods to rank the airlines competitiveness needs to be explored further. For this purpose, it will conduct reasonable allocation of traffic rights resources effectively.

\section{Data Availability}

The data in this paper are on the topic of safety and operation of airlines. They are from Civil Aviation Administration of China. The processed data used to support the findings of this study are included within the article. The raw data used to support the findings of this study are available from the corresponding author upon request.

\section{Conflicts of Interest}

The authors declare that they have no conflicts of interest.

\section{Acknowledgments}

This work was funded by the National Natural Science Foundation of China (project no. 71871013).

\section{References}

[1] A. G. Assaf and A. Josiassen, "The operational performance of UK airlines: 2002-2007," Journal of Economic Studies, vol. 38, no. 1, pp. 5-16, 2011.

[2] T. J. Hannigan, R. D. Hamilton, and R. Mudambi, "Competition and competitiveness in the US airline industry," Competitiveness Review, vol. 25, no. 2, pp. 134-155, 2015.

[3] X. S. Li, "Research on evaluation of the competitiveness of domestic and foreign airlines based on matter-element model," Communications in Computer \& Information Science, vol. 268, 2012.

[4] I. Vlachos and Z. Lin, "Drivers of airline loyalty: evidence from the business travelers in China," Transportation Research Part E: Logistics and Transportation Review, vol. 71, pp. 1-17, 2014.

[5] R. Merkert and J. Pearson, "A non-parametric efficiency measure incorporating perceived airline service levels and profitability," Journal of Transport Economics and Policy, vol. 49, pp. 261-275, 2015.

[6] W. Zhen and L. I. Xue-Gong, "Evaluation and research of port competitiveness based on FAHP," Port \& Waterway Engineering, vol. 5, pp. 964-971, 2011.

[7] H. S. Jenatabadi and N. A. Ismail, "Application of structural equation modelling for estimating airline performance," Journal of Air Transport Management, vol. 40, pp. 25-33, 2014.

[8] S.-J. Joo and K. Fowler, "Exploring comparative efficiency and determinants of efficiency for major world airlines," Benchmarking: An International Journal, vol. 21, no. 4, pp. 675-687, 2014.

[9] C. Wu, X.-Y. Zhang, I.-C. Yeh, F.-Y. Chen, J. Bender, and T.-N. Wang, "Evaluating competitiveness using fuzzy analytic hierarchy process-A case study of Chinese airlines," Journal of Advanced Transportation, vol. 47, no. 7, pp. 619-634, 2013.

[10] T. Fischer and D. R. Kamerschen, "Measuring competition in the U.S. Airline industry using the rosse-panzar test and crosssectional regression analyses," Journal of Applied Economics, vol. 6, no. 1, pp. 73-93, 2003. 
[11] S. Borenstein, "An index of inter-city business travel for use in domestic airline competition analysis," in Proceedings of the NBER Working Paper, Cambridge, MA, USA, 2010.

[12] J. K. Brueckner, D. Lee, and E. S. Singer, "Airline competition and domestic US airfares: a comprehensive reappraisal," Economics of Transportation, vol. 2, no. 1, pp. 1-17, 2013.

[13] Y.-H. Chang and C.-H. Yeh, "Evaluating airline competitiveness using multiattribute decision making," Omega, vol. 29, no. 5, pp. 405-415, 2001.

[14] T. H. Oum and C. Yu, "Cost competitiveness of major airlines: an international comparison," Transportation Research Part A: Policy and Practice, vol. 32, no. 6, pp. 407-422, 1998.

[15] P. J. G. Pineda, J. J. Liou, C. C. Hsu, and Y. C. Chuang, “An integrated MCDM model for improving airline operational and financial performance," Journal of Air Transport Management, vol. 68, pp. 103-117, 2018.

[16] J. Raheleh and Y. Wen, "Fuzzy modeling for uncertainty nonlinear systems with fuzzy equations," Mathematical Problems in Engineering, vol. 2017, pp. 1-10, 2017.

[17] L. Moir and G. Lohmann, "A quantitative means of comparing competitive advantage among airlines with heterogeneous business models: analysis of U.S. airlines," Journal of Air Transport Management, vol. 69, pp. 72-82, 2018.

[18] K. Yeh and C. W. Chen, "Stability analysis of interconnected fuzzy systems using the fuzzy lyapunov method," Mathematical Problems in Engineering, vol. 2010, pp. 23.1-23.10, 2010.

[19] H. A. Linstone and M. Turoff, The Delphi Method: Techniques and Applications, Addison-Wesley, Reading, MA, USA, 2002.

[20] T. L. Saaty, "Decision making with the analytic hierarchy process," International Journal of Services Sciences, vol. 1, no. 1, p. 83, 2008.

[21] S. A. Delbari, S. I. Ng, Y. A. Aziz, and J. A. Ho, “An investigation of key competitiveness indicators and drivers of fullservice airlines using Delphi and AHP techniques," Journal of Air Transport Management, vol. 52, pp. 23-34, 2016.

[22] J. Yu and Y. Li, "Multi-level fuzzy comprehensive evaluation method for airline competitiveness," Journal of Transportation Engineering, vol. 8, no. 3, pp. 116-121, 2008, in Chinese.

[23] $\mathrm{P} . \mathrm{Fu}$ and $\mathrm{C}$. $\mathrm{Wu}$, "Research on competitive evaluation of domestic airlines based on FAHP method," Journal of Suzhou University, vol. 1, no. 2, pp. 131-136, 2011, in Chinese.

[24] Y. Li, J. Yu, and Y. Wu, "Evaluation and empirical study of airline competitiveness," Journal of Beijing Institute of Technology (Social Science Edition), vol. 11, no. 4, pp. 49-53, 2009, in Chinese.

[25] W. Li and C. Wu, "Research on airline competitiveness based on secondary relative evaluation," Journal of Wuhan University of Technology (Information and Management Engineering Edition), vol. 1, no. 10, pp. 846-850, 2011, in Chinese.

[26] A. Charnes, W. W. Cooper, and E. Rhodes, "Measuring the efficiency of decision making units," European Journal of Operational Research, vol. 2, no. 6, pp. 429-444, 1978.

[27] P. Andersen and N. C. Petersen, "A procedure for ranking efficient units in data envelopment analysis," Management Science, vol. 39, no. 10, pp. 1261-1264, 1993.

[28] B. Marian, "Gorzałczany and filip rudziński, evolution of SOMs' structure and learning algorithm: from visualization of high-dimensional data to clustering of complex data," Algorithms, vol. 13, no. 5, p. 109, 2020.

[29] H. Simon, Neural Network Principle, China Machine Press, Beijing, China, 2004.
[30] T. Kohinen, "Self-organized formation of topologically correct feature maps," Biological Cybernetics, vol. 4, no. 3, pp. 59-69, 1982.

[31] M. Y. Kiang, "Extending the Kohonen self-organizing map networks for clustering analysis," Computational Statistics \& Data Analysis, vol. 38, no. 2, pp. 161-180, 2001.

[32] J. Zhang, "Transformer fault diagnosis based on SOM," Journal of Electric Power, vol. 29, no. 4, pp. 318-321, 2014.

[33] Y. S. Qian, M. Wang, H. X. Kang et al., "Study on the road network connectivity reliability of valley city based on complex network," Mathematical Problems in Engineering, vol. 2012, no. 9, pp. 430785.1-430785.14, 2012.

[34] Y. Liu and L. Chen, "Mechanical fault diagnosis of vacuum circuit breaker based on som," Transaction of China Electrotechnical Society, vol. 32, no. 5, pp. 49-54, 2017.

[35] K. Xie, Y. Yang, Y. Xin et al., "Cellular neural network-based methods for distributed network intrusion detection," Mathematical Problems in Engineering, vol. 2015, no. 3, pp. 343050.1-343050.10, 2015.

[36] Z. Duan, K. Zhang, Z. Chen et al., "Prediction of city-scale dynamic taxi origin-destination flows using a hybrid deep neural network combined with travel time," IEEE Access, vol. 7, no. 99, 2019.

[37] L. Lei, W. Shi, and M. Fan, "Water quality evaluation analysis based on improved SOM neural network," Chinese Journal of Scientific Instrument, vol. 30, no. 11, pp. 2379-2383, 2009.

[38] Y. Du and Q. Tian, "Performance evaluation for mechanical products based on fuzzy neural network," Systems Engineering and Electronics, vol. 27, no. 9, pp. 1583-1586, 2005.

[39] J. Zhao and X. Chen, "Evaluation and analysis of airlines' operation and service quality based on grey system theory," in Proceedings of the 2020 IEEE International Conference on Civil Aviation Safety and Information Technology(ICCASIT 2020), Weihai, China, 2020.

[40] X. Xie, Domestic Airline Competitiveness Evaluation Evaluation Based on Principal Component Analysis, Harbin Institute of Technology, Harbin, China, 2011, in Chinese. 